\title{
The Assessment of Epicardial Adipose Tissue in Acute Coronary Syndrome Patients. A Systematic Review
}

\author{
Theodora Benedek ${ }^{1,2}$, Nora Rat ${ }^{1,2}$, Roxana Hodas ${ }^{1}$, Diana Opincariu ${ }^{1}$, András Mester ${ }^{1}$, \\ Imre Benedek ${ }^{1,2}$ \\ ${ }^{1}$ Center of Advanced Research in Multimodality Cardiac Imaging, Cardio Med Medical Center, Tîrgu Mureș, Romania \\ ${ }^{2}$ Clinic of Cardiology, University of Medicine and Pharmacy, Tîrgu Mureș, Romania
}

\section{ABSTRACT}

Background: This systematic review seeks to evaluate the role of epicardial adipose tissue (EAT), quantified either by thickness, assessed by transthoracic echocardiography, or by volume, assessed by cardiac computed tomography (CT), in the follow-up of patients with acute coronary syndromes (ACS). Method: One-hundred forty-four articles were screened, from which 56 were reviewed in full-text. From those, 47 studies were excluded for the following reasons: they did not meet the inclusion criteria; they were either reviews or meta-analyses; the study cohorts included only stable coronary artery disease patients; they did not state a clear and concise study design, endpoints, or follow-up. The final draft included nine studies for systematic evaluation. Results: Of the 2,306 patients included in the review, 170 underwent cardiac CT while the remaining 2,136 underwent transthoracic echocardiography for the measurement of EAT. The analysis found that the EAT thickness was significantly associated with major adverse cardiovascular events (MACE) rates during hospitalization (OR: $-1.3,95 \%$ CI: 1.05-1.62, $\mathrm{p}=0.020$ ) and at three years (HR: 1.524, 95\% CI: 1.0-2.2, p = 0.038). The included studies found that EAT was correlated with the following clinical and angiographic risk scores for ACS: GRACE $(r=0.438, p<0.001)$, TIMI risk score $(r=0.363, p=0.001)$, SYNTAX score $(r$ $=0.690, \mathrm{p}<0.0001 ; \mathrm{r}=0.610, \mathrm{p}<0.01)$, and Gensini score $(\mathrm{r}=0.438, \mathrm{p}=0.001)$. There was an inverse correlation between ST-segment resolution of $<70 \%$ after revascularization and EAT ( $r$ $=-0.414, \mathrm{p}=0.01)$, and the myocardial blush grade $(\mathrm{r}=-0.549, \mathrm{p}<0.001)$. The EF aggregation ranged between $2.65 \mathrm{~mm}$ and $4.7 \mathrm{~mm}$ within the included studies. Conclusions: EAT, evaluated either by echocardiography or cardiac CT, correlates with the severity of coronary lesions, with the clinical and angiographic risk scores for acute coronary syndromes, with indicators for coronary reperfusion, and with short- and long-term MACE rates. Further studies are required to fully elucidate the role of this extensively studied but still novel cardiovascular biomarker as part of a risk prediction tool.

Keywords: epicardial adipose tissue, acute coronary syndromes, echocardiography, cardiac CT

\section{ARTICLE HISTORY}

Received: 11 October, 2016

Accepted: 3 November, 2016

\section{CORRESPONDENCE}

Diana Opincariu

Str. 22 Decembrie 1989 nr. 76

540124 Tîrgu Mureș, Romania

Tel: +40 265217333

E-mail: diana.opincariu@yahoo.ro

Theodora Benedek: Str. Gheorghe Marinescu nr. 38, 540139 Tîrgu Mureș, Romania. Tel: +40 265215 551. E-mail: theodora.benedek@gmail.com 


\section{INTRODUCTION}

Acute coronary syndromes remain a leading cause of death worldwide despite the many advances in both preventive strategies and emergency treatment options, including percutaneous coronary interventions. ${ }^{1}$

Several predictors of the severity of coronary artery disease have been established, and, in recent years, attention has been directed towards the role of epicardial adipose tissue (EAT) as a cardiovascular risk factor, as well as the assessment of instability of atherosclerotic coronary plaques. $^{2}$

\section{EAT - ROLE AND PATHOPHYSIOLOGY}

Adipose tissue surrounding the heart has several roles, including being an energy provider for myocardial metabolism, thermoregulation, and mechanical protection for both the epicardial coronary vessels and the autonomic innervation of the heart. ${ }^{3}$ The metabolic and immunologic effects of EAT remain unclear, although several hypotheses have been suggested, including that of secreting increased quantities of anti- and pro-inflammatory cytokines, regulating the oxidative reactions within the myocardial fibers, as well as influencing the contractility, conductibility, and excitability of the heart. ${ }^{4}$

Furthermore, being a visceral fat and having the same characteristics and behavior as intra-abdominal fat, EAT appears to be one of the extra-vascular culprits associated with the progression and aggravation of atherosclerotic lesions. ${ }^{5}$

The genesis of a coronary atheroma is influenced, in various stages, by the adipose tissue surrounding the heart, from intimal malfunction at an early stage, to plaque erosion and rupture, with subsequent thrombosis and the occurrence of an acute coronary syndrome. ${ }^{6,7}$

Histopathological studies of epicardial fat samples acquired during cardiac surgery have shown that EAT contains several inflammation biomarkers, including tumor necrosis factor- $\alpha$, interleukins, and chemokines, which might contribute to the development and progression of insulin resistance, and also enhance apoptosis within the coronary plaque and vessel inflammation. ${ }^{8}$

On the other hand, epicardial adipose tissue has beneficial effects by secreting adiponectin - with anti-inflammatory and anti-atherogenic properties and also by stimulating neo-angiogenesis in subjects with chronic coronary occlusions. ${ }^{8,9}$

\section{EAT IN CORONARY ATHEROSCLEROSIS AND ACUTE CORONARY SYNDROMES}

EAT has been shown to be linked with the presence and severity of coronary atherosclerotic lesions. ${ }^{10,11}$ Subjects with an increased EAT, assessed either by echocardiography or cardiac CT, have a more severe extension of coronary atherosclerosis, and EAT is also linked to the overall plaque burden and cardiovascular risk factors. ${ }^{12-14}$ Furthermore, the incidence of myocardial infarction seems to be directly proportional to the increase in epicardial fat, which is also related to a higher rate of major adverse cardiovascular events in subjects with known coronary artery disease (CAD). ${ }^{15,16}$ Due to its paracrine properties, by secreting serum inflammatory biomarkers EAT brings a significant contribution to the vulnerability of the coronary atheromatous plaque, either by local inflammation or by stimulating neo-angiogenesis and the development of vasa-vasorum and subsequent intra-plaque hemorrhage, plaque rupture and thrombosis. ${ }^{15,17,18}$ Patients without chest pain who present with major adverse cardiovascular events have a bigger epicardial fat volume compared to event-free patients. ${ }^{19}$ The coronary artery calcium score, a marker of CAD severity, has a positive correlation with EAT in patients with both obstructive and non-obstructive CAD. An increased EAT volume, together with low attenuation plaques with the presence of a napkin-ring sign, are correlated with a higher risk of future acute coronary events in non-obese subjects. ${ }^{20,21}$ Moreover, the thickness of the epicardial fat has been shown to be closely linked to the presence of multi-vessel CAD in patients with acute myocardial infarction. ${ }^{22}$

\section{EAT - METHODS OF ASSESSMENT AND IMAGING TECHNIQUES}

The imaging methods for assessing epicardial fat include 2D transthoracic echocardiography (TTE), native cardiac computed tomography and magnetic resonance imaging (MRI). ${ }^{23}$ MRI remains the gold-standard technique for measuring not only the adipose tissue surrounding the heart but also the total visceral fat. Despite the fact that MRI allows the acquisition of high-resolution images and the possibility of quantifying EAT volume, it is not feasible in an emergency clinical setting, as it is more costly and less available than other methods. ${ }^{24}$

Transthoracic 2-dimensional echocardiography is a low-cost and easily available, non-invasive method that allows the quantification of epicardial fat. It has been proven to be as useful as more advanced imaging meth- 
ods such as CT or MRI. ${ }^{25}$ The 2-D TTE measurement of epicardial fat thickness is expressed in millimeters and is performed with the patient in a lateral decubitus position, at the level of the free wall of the right ventricle, from a parasternal long axis view, in three consecutive cardiac cycles, at the end-diastolic period. ${ }^{26}$ EAT is illustrated on TTE as a hypoechoic space between the epicardium and pericardium. The consensus of opinion is that a value of $>5 \mathrm{~mm}$ should be considered suggestive of an increased EAT. ${ }^{23,26-29}$ TTE assessment of EAT has several limitations, including inter- and intra-observer variability, as well as the location of epicardial fat on the surface of the heart and the phases of the cardiac cycle in which the measurements are done..$^{30}$ Further drawbacks include problems in discriminating between epicardial and pericardial material or fluid in the pericardial sack. ${ }^{26}$

Cardiac computed tomography (CT) examination can accurately assess the volume, total area, and thickness of epicardial adipose tissue, and concomitantly it can evaluate coronary atheromas and their degree of calcification. ${ }^{23,31}$ EAT can be measured by CT at the level of the free wall of the right ventricle, in the atrioventricular and interventricular spaces, and also in the proximity of the main coronary vessels, when it is regularly associated with coronary calcium score evaluation. ${ }^{23}$ Similarly to TTE assessment, EAT volume measured by CT does not have a precise range considered as normal. A study (2008) stated the average EAT volume was $110 \pm 41 \mathrm{ml}$ in females and 137 $\pm 53 \mathrm{ml}$ in males, ${ }^{32}$ and Shmilovich et al. (2011) reported that epicardial fat volume indexed to the whole body surface area, at the 95th percentile, was $68.1 \mathrm{ml} / \mathrm{m} 2 .{ }^{33}$ The limitations of this technique are represented by the difficulty of achieving standard location limits for the measurements and by the inter-observational variability. 34,35

\section{MATERIALS AND METHOD}

\section{SEARCH STRATEGY}

The study was conducted in agreement with the PRISMA methodology (Preferred Reporting Items for Systematic Reviews and Meta-Analyses). ${ }^{36}$

The literature search was centered on accessing all published articles related to epicardial adipose tissue evaluation in acute coronary syndrome patients, either by TTE or cardiac CT.

Two investigators searched the PubMed/Medline and Thomson Reuters scientific databases. The comprehensive search strategy comprised the following medical subject headings (MeSH) terms: "epicardial fat AND acute coro- nary syndromes", "epicardial adipose tissue AND acute coronary syndromes", "epicardial fat thickness", "epicardial fat volume".

\section{DATA EXTRACTION AND ANALYSIS}

The two investigators extracted the following data from the selected manuscripts: the number of subjects included in the study, age, gender, type of acute coronary syndrome for which they had been admitted, the follow-up period, the primary and secondary endpoints, the method of assessment of EAT, the mean values (TTE) and volume (cardiac CT) of EAT respectively, as well as the presence of diabetes, smoking, hypertension history, obesity. Furthermore, whenever available, data extraction included the odds ratios (OR) and hazard ratios (HR) when appropriate for the endpoints of each study.

\section{STUDY QUALITY ASSESSMENT AND ELIGIBILITY CONDITIONS}

No study was excluded for motives of decreased study quality, but the selected studies presented a concise portrayal of the inclusion and exclusion criteria, the endpoints and the follow-up periods, as well as a precise method for assessing the EAT, irrespective of the noninvasive method that had been used (TTE or cardiac CT). Articles that enrolled only subjects with stable CAD were excluded from the search. Also, we excluded various articles such as case reports, case series, reviews, editorials, letters, as well as manuscripts that were not available in full-text form. The search filter also excluded species other than humans.

\section{RESULTS}

One-hundred forty-four manuscripts were screened in total, out of which 56 were identified using the described search strategy and were reviewed in a full-text form. From those, 47 studies were excluded for not meeting the inclusion criteria. These were either reviews or metaanalyses, the study cohorts included only stable coronary artery disease patients, or they did not state a clear and concise study design, endpoints or follow-up (Figure 1). The final draft included nine studies for systematic evaluation: one study that used CT for EAT assessment, and eight manuscripts that assessed EAT with TTE.

In all, 2,306 patients were included, of which 170 subjects underwent cardiac CT for EAT evaluation, ${ }^{37}$ while the remaining 2,136 patients underwent TTE measure- 


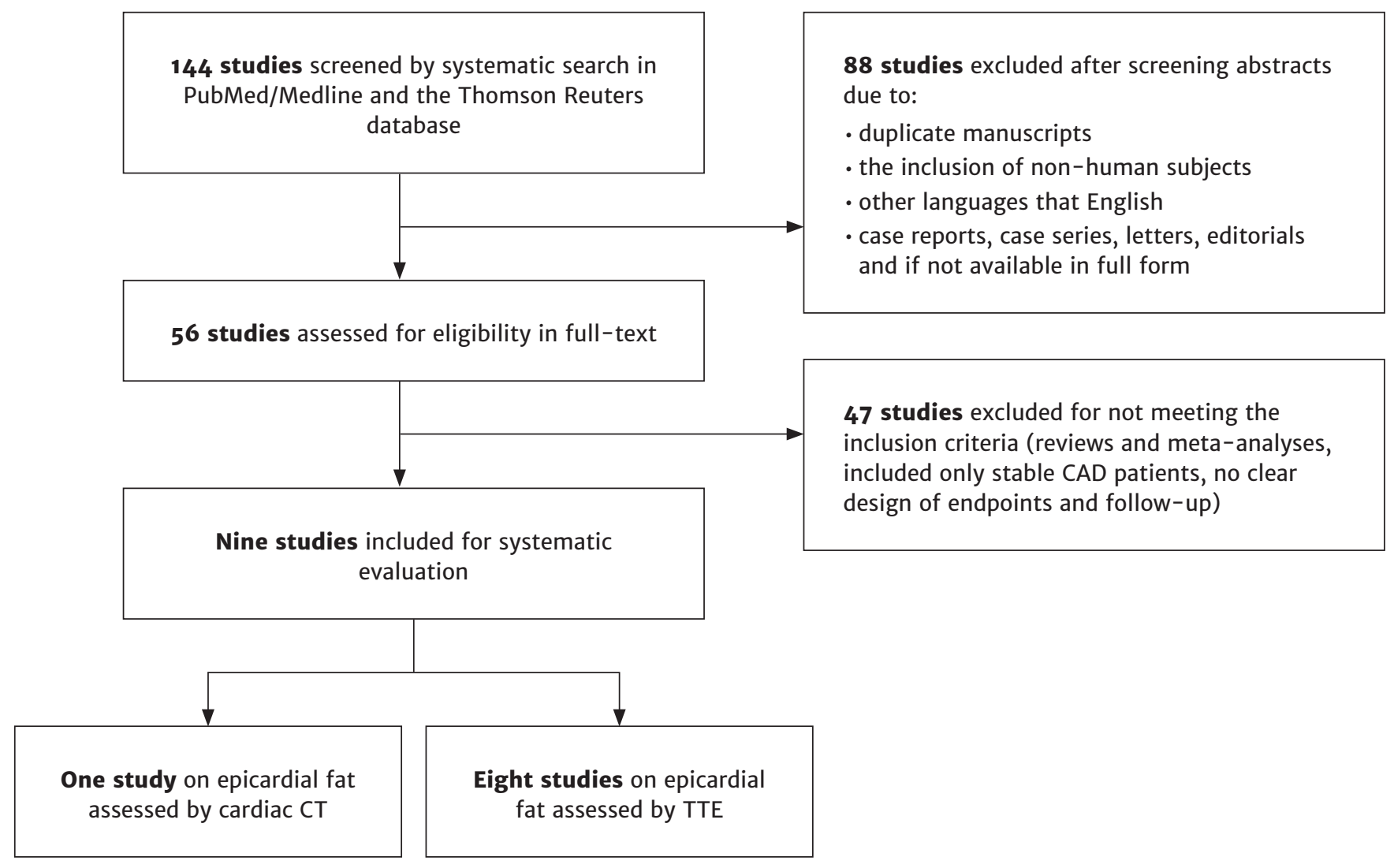

FIGURE 1. Diagram of the search protocol and results of manuscript selection

ment of EAT. ${ }^{38-45}$ Table 1 presents a summary of the included manuscripts. All systematized manuscripts contain a concise and clear portrayal of the inclusion and exclusion criteria and the method for assessing EAT, either through cardiac CT or TTE (Table 1). All studies enrolled patients with acute coronary syndromes. Six of the nine studies used, as one of the main exclusion criteria, previous revascularization therapies, either by coronary artery bypass grafting or percutaneous coronary intervention.

\section{CHARACTERISTICS OF THE STUDY POPULATIONS}

The overall characteristics of the patients included in the nine study cohorts, including cardiovascular risk factors and gender distribution, are listed in Table 2.

\section{STATISTICAL ANALYSIS AND STUDY DESIGN OF THE SELECTED MANUSCRIPTS}

There was a diversity of study methodology and statistical approaches used in the selected manuscripts. Four studies were retrospective and calculated odds ratios based on multivariate logistic regression. From the five prospective observational studies, only one used Cox proportional hazards models for the prediction of major adverse cardiovascular events (MACE) rates during the three-year follow-up. ${ }^{42}$ Most researchers $(n=6)$ used the Receiver Operator Characteristics (ROC) curve and the area under the curve for the determination of the cut-off value for EAT values that predicted the study outcome..$^{37-41,45}$ All selected articles used Spearman or Pearson correlation coefficient statistics for evaluating the link between epicardial fat and other clinical and laboratory variables.

\section{STUDY ENDPOINTS AND RESEARCH HYPOTHESES}

\section{EAT and MACE}

Two manuscripts examined the prognostic value of EAT, and the endpoints included the in-hospital MACE rates. ${ }^{40}$ One study 42 had a three-year follow-up period, with major adverse cardiovascular events as a primary endpoint. Both survival studies included multivariate adjustments for cardiovascular risk factors (smoking, diabetes, age) as well as medical history (previous cardiovascular and 


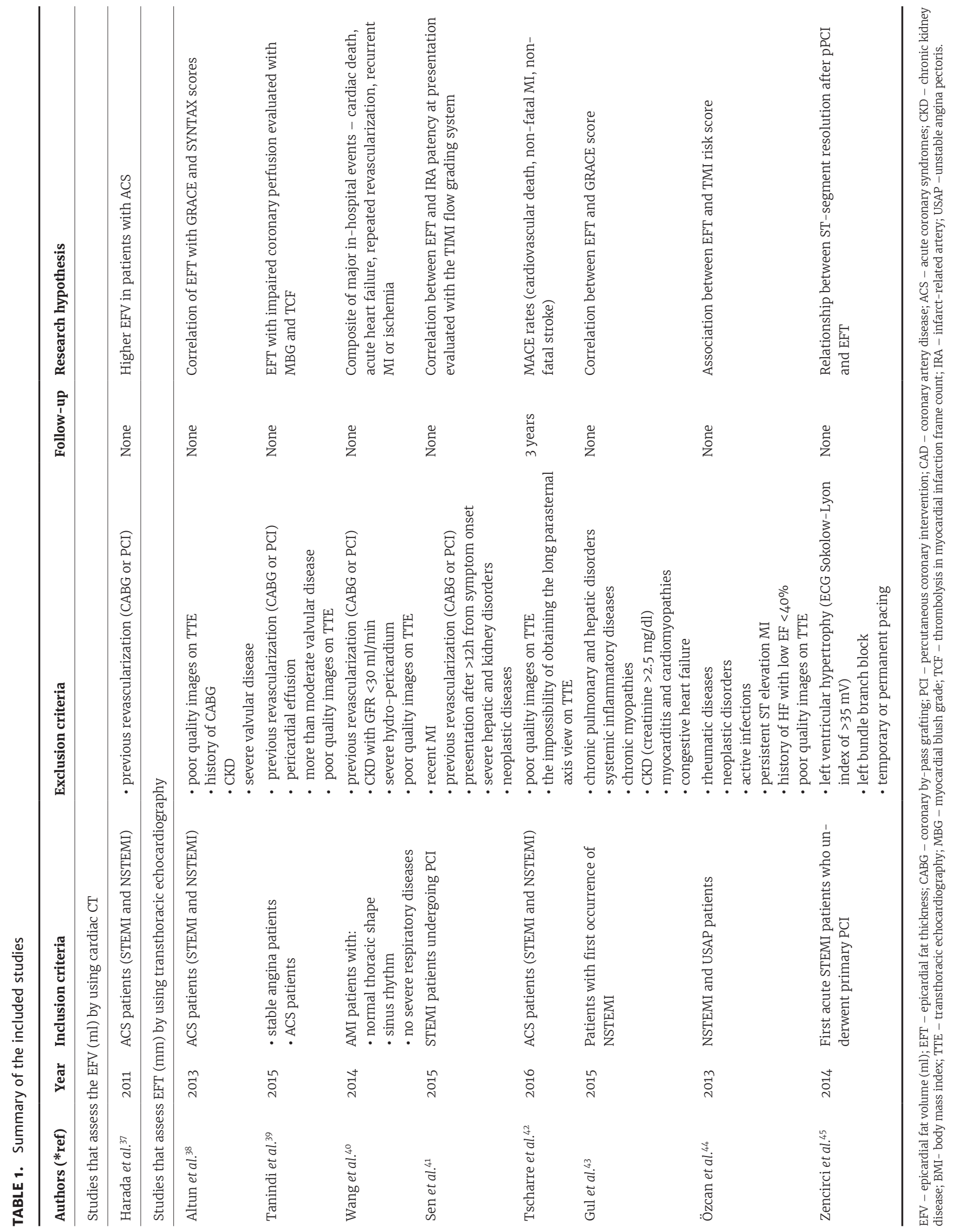




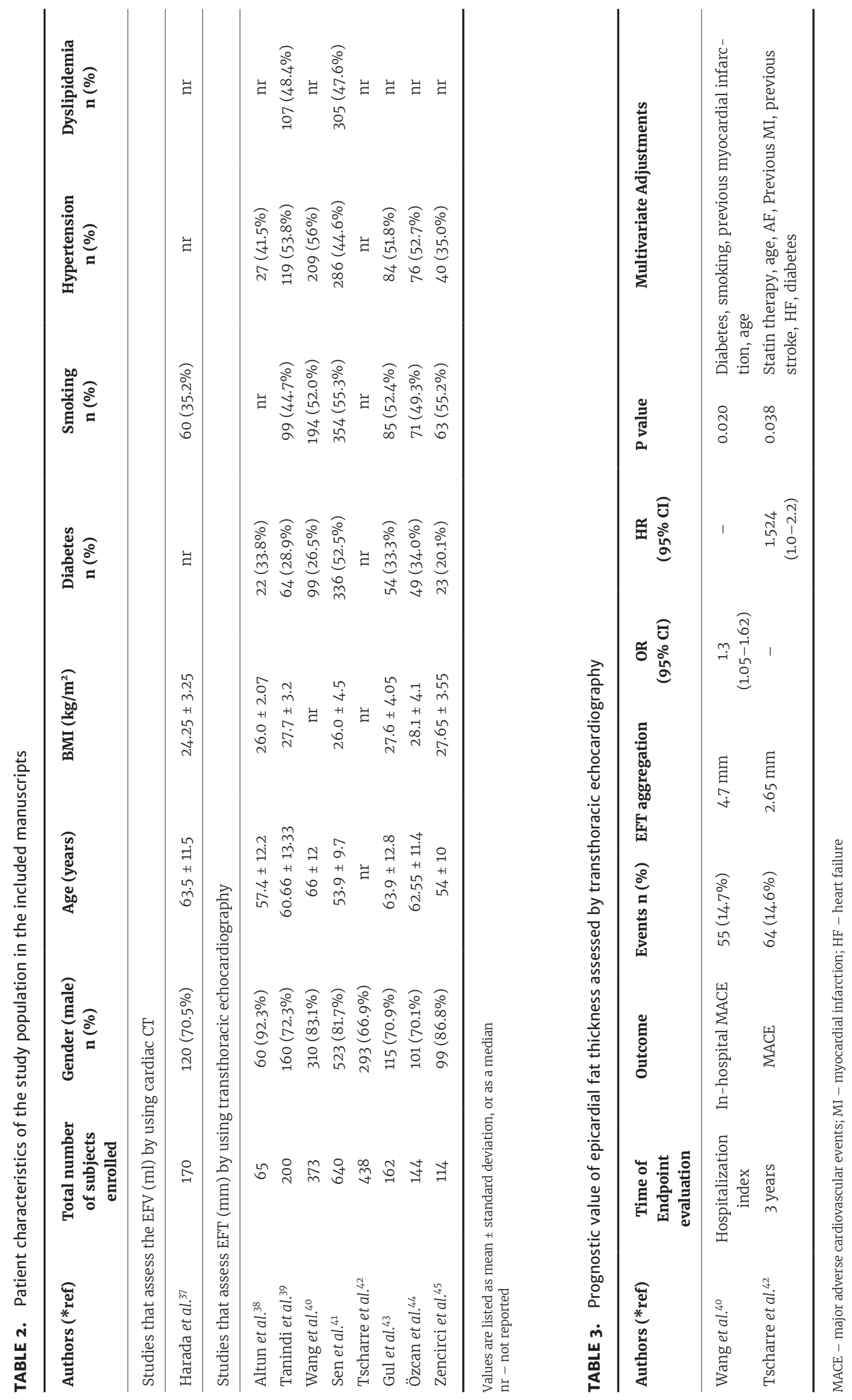


TABLE 4. EFT and risk scores for acute coronary syndrome

\begin{tabular}{|c|c|c|c|c|c|}
\hline Study & Risk score & Risk score value & EFT aggregation & $\begin{array}{l}\text { Correlation } \\
\text { coefficient } r / \beta\end{array}$ & $P$ value \\
\hline \multirow[t]{2}{*}{ Altun et al..$^{38}$} & GRACE & $101.8 \pm 33.1$ & $5.5 \mathrm{~mm}$ & 0.224 & 0.072 \\
\hline & SYNTAX & $11.5 \pm 5.6$ & $5.5 \mathrm{~mm}$ & 0.690 & $<0.0001$ \\
\hline \multirow[t]{2}{*}{ Tanindi et al..$^{39}$} & MBG & $1.7 \pm 1.16$ & $>7 \mathrm{~mm}$ & -0.549 & $<0.001$ \\
\hline & TFC & $35.02 \pm 7.7$ & $>7 \mathrm{~mm}$ & 0.757 & $<0.001$ \\
\hline Gul et al. 43 & GRACE & $\mathrm{nr}$ & $4.68 \mathrm{~mm}$ & 0.438 & $<0.001$ \\
\hline \multirow[t]{2}{*}{ Özcan et al.44 } & TIMI RS & 5.2 & $8.2 \pm 2.1 \mathrm{~mm}$ & 0.363 & 0.001 \\
\hline & Gensini & $54.3 \pm 17.5$ & $8.2 \pm 2.1 \mathrm{~mm}$ & 0.442 & 0.001 \\
\hline Zencirci et al. ${ }^{45}$ & $\begin{array}{l}\text { ST segment resolution after PCI } \\
(\triangle \text { STR })\end{array}$ & $<70 \%$ & $5.5 \pm 2 \mathrm{~mm}$ & -0.414 & 0.01 \\
\hline
\end{tabular}

GRACE - global registry of acute coronary events risk score; SYNTAX -; MGB - myocardial blush grade; TFC - TIMI frame count; nr - not reported; TIMI RS - thrombolysis in myocardial infarction risk score; PCI - percutaneous coronary intervention; $\triangle \mathrm{STR}$ - difference between the sum of ST segment elevations before and after revascularization

cerebrovascular events, heart failure) (Table 3). Wang et al. (2014) showed that there is a significantly higher rate of MACE during hospitalization for acute myocardial infarction in patients with an EAT thickness of $>4.7 \mathrm{~mm}(\mathrm{p}=$ 0.02) after multivariate adjustments..$^{40}$ The other study on the prognostic value of EAT, on ST-elevation myocardial infarction (STEMI) versus non-ST-elevation myocardial infarction (NSTEMI) patients, revealed that a median EAT thickness of $2.6 \mathrm{~mm}$ (interquartile range 2.00-3.00) had a significant predictive capacity for the primary endpoint on both univariate (HR: 1.479, 95\% CI: 1.192-1.953, p = 0.006) and multivariate (HR: 1.524, 95\% CI: 1.011-2.267, p $=0.038)$ Cox regression analysis..$^{42}$

\section{EAT and ACS risk scores}

Seven manuscripts evaluated the correlation between EAT (measured with TTE) and various ACS risk scores (Table 4). ${ }^{38-41,43-45}$ Zencirci et al. (2014) hypothesized that there is an inverse association between the EAT and the STsegment resolution following primary PCI for acute STEMI. ${ }^{45}$ Other studied risk scores are the SYNTAX score for coronary atherosclerosis severity, the GRACE and TIMI risk scores for survival following an acute cardiac event, and also indicators for coronary perfusion after PCI (TIMI flow, myocardial blush grade - MBG, and TIMI frame count - TFC) (Table 4).

The overall results of the manuscripts that evaluated risk scores state that there are statistically significant correlations between an increased EAT thickness and enhanced integer values of the calculated risk scores and low perfusion indicators.

\section{EAT and acute coronary syndromes}

Of the 2,306 patients, 1,527 presented with STEMI, 378 with NSTEMI, and thirty-four with unstable angina pectoris. Furthermore, two of the manuscripts included, in addition to patients with ACS, stable angina pectoris patients or subjects with suspected CAD, which acted as a control group. ${ }^{37,39}$ Harada et al. (2011) evaluated EAT using cardiac $\mathrm{CT}$ and compared epicardial fat volume (EFV, $\mathrm{ml}$ ) in subjects with ACS $(n=80)$ and controls $(n=90)$. There was no significant coronary artery stenosis, and healthy individuals had a significantly lower EFV compared to the case lot ( $\mathrm{p}$ $<0.001$ ). Tanindi et al. (2015) showed that patients with AMI have a significantly higher EAT thickness compared to unstable angina or stable CAD patients ( $\mathrm{p}<0.001)^{39}$ (Table 5).

EAT assessed by TTE was variable among study measurements, the mean ranging from a minimum of 2.65 $\mathrm{mm}$, to a maximum of $8.5 \pm 1.4 \mathrm{~mm}$ (Table 5 ).

\section{DISCUSSIONS}

Although study design in the available research articles was not constant, the prognostic value of EAT in ACS and the possible correlations between EAT and ACS risk scores and coronary perfusion indicators were appraised. Despite not being consistent, the results indicated that EAT tends to negatively impact the outcome, the risk of further adverse events, and the success of coronary revascularization procedures.

The role of epicardial fatty tissue has been extensively studied, and its pathophysiology is now better known, showing both positive and negative bearings on the development and progression of CAD. ${ }^{3-9}$ 


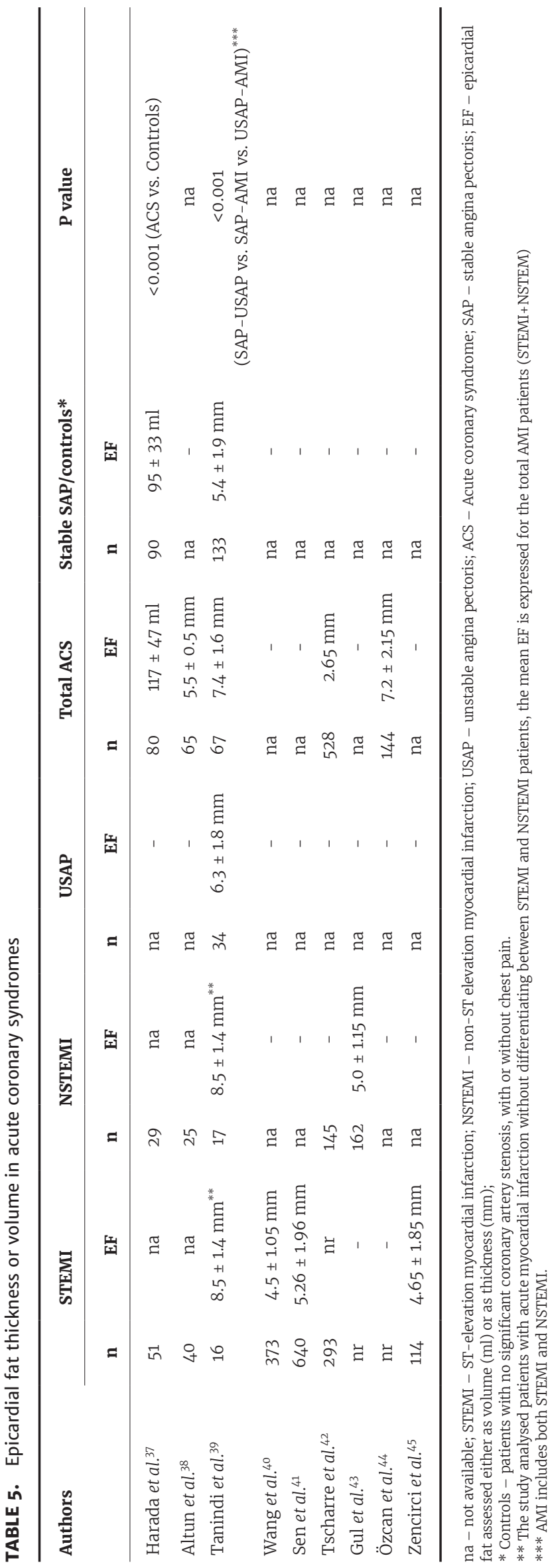

There is evidence that EAT is in direct relation with the body mass index and the presence of obesity, and it is also increased in patients with metabolic syndromes. ${ }^{32,46-48}$

Epicardial fat has also been linked to an increased systemic inflammatory status in type 2 diabetes patients with acute myocardial infarction, and in patients with a higher EAT thickness it was associated with an enhanced left ventricular remodeling process and lower ejection fraction at six months. 49

Further studies are needed to elucidate the effect of a reduction of EAT on risk diminution, although some researchers have proved that the regression of $\mathrm{EF}$ can be achieved with weight loss measures, dietary modifications, regular physical exercise, and lipid-lowering therapies with statins and ezetimibe. ${ }^{28,50-52}$

Coronary artery plaque burden was shown to be associated with a higher quantity of epicardial fat..$^{53}$ Several studies have stated that there is a relationship between an increased EAT and plaque vulnerability. ${ }^{54-56}$ Noninvasive imaging biomarkers, identified by computed tomography coronary angiography, include the coronary artery calcium score, low-density plaques with an increased necrotic core, the presence of spotty calcifications and the napkinring sign. ${ }^{57,58}$ Biomarkers for plaque instability, detected by advanced imaging methods such as intravascular ultrasound (IVUS) and optical coherence tomography (OCT) include the thick fibrous cap atheroma, fibrous cap thickness, the extent of intra-plaque macrophage deposition, vessel extension and rupture. ${ }^{59-61}$

Two of the largest EAT studies included cohorts of patients with no cardiovascular disease. The MESA trial/ study showed a positive association between the coronary artery calcium score and the EFV assessed by CT, but the Heinz-Nixdorf Recall study found that EAT predicted an excessive risk for coronary events, independently of the calcium score and classic cardiovascular risk factors. ${ }^{15,62}$ The studies analyzed in our systematic review did not include manuscripts that had evaluated coronary calcium or vulnerable plaque biomarkers, as these did not meet the inclusion criteria.

\section{EAT AND ACS RISK SCORES}

Ongoing research is being undertaken to identify additional risk markers which could predict future cardiovascular events after an ACS. Several risk scores have been developed for risk assessment in ACS, including GRACE (Global Registry of Acute Coronary Events), SYNTAX, the TIMI risk score, all of which have been validated in predicting MACE rates. ${ }^{63-65}$ 
Our systematic analysis showed that several investigations have studied the correlation between EAT thickness and established ACS risk scores. ${ }^{38,43-45}$ One study ${ }^{43}$ found a significant association between EAT and GRACE scores ( $p$ $<0.001$ ), though this was not corroborated by other studies. ${ }^{38}$ The angiographic SYNTAX score for coronary lesion severity and the clinical TIMI risk score for adverse coronary events were also found to be significantly linked with EAT. ${ }^{38,40,44}$ Being associated with ACS severity and risk prediction scores and connected with markers that express an increased patient vulnerability for acute coronary syndromes, at the same time being proven as an independent $C A D,{ }^{53}$ EAT qualifies as a candidate for inclusion in current ACS risk scores.

One of the included studies hypothesized that an increased thickness of the epicardial fat is linked to impairment in the ST-segment resolution following revascularization in acute MI patients. ${ }^{45} \mathrm{ST}$-segment resolution is a surrogate for tissue level reperfusion, illustrating the no-reflow phenomenon after primary PCI, and the lack of ST-segment regression after PCI has been proved to be a predictor for in-hospital mortality rates. ${ }^{66,67}$

\section{EAT AND MAJOR ADVERSE CARDIOVASCULAR EVENTS}

Epicardial fat might provide supplementary evidence regarding future cardiac events in patients with acute coronary syndromes. It is well known that an increased systemic inflammatory status leads to a poorer outcome in patients with STEMI. ${ }^{68,69}$ Being an active metabolic tissue that secretes inflammatory cytokines and chemokines, epicardial fat could contribute to the overall inflammation, thus negatively impacting the outcome of ACS patients.4 EAT thickness can be used as a predictor of MACE, including MI and cardiovascular death. ${ }^{70}$ Furthermore, an increased EF volume was shown to predict MI or cardiovascular death in patients suspected of CAD. ${ }^{71}$ In a study that compared MACE individuals with eventfree controls, patients with MACE had a significantly higher EF volume, even after multivariate adjustments for age, BMI, coronary calcium score, and Framingham risk score. ${ }^{72}$

The present review included two studies that evaluated the MACE rate with different endpoint evaluation times. ${ }^{40,42}$ Wang et al. (2014) evaluated the influence of EAT thickness on the rate of major events during hospitalization, and after multivariate adjustments, concluded that the cut-off value for epicardial fat thickness (EFT) was $4.7 \mathrm{~mm}$ for predicting the primary endpoint (OR: 0.13, 95\% CI: 1.05-1.62)..$^{40}$ Tscharre et al. (2016) concluded that
EFT was predictive for MACE rates during a follow-up period of three years (HR: 1.524, 95\% CI: 1.0-2.2).42

\section{EAT - ECHOCARDIOGRAPHY VERSUS CARDIAC CT}

EAT, appraised by echocardiography, was shown to be associated with the EFV assessed by CT. ${ }^{25,26}$ While cardiac CT and MRI allow the volumetric assessment of endocardial adipose tissue, echocardiography determines only the regional thickness of EAT. Since a close relationship has been shown to exist between EAT volume and thickness, echocardiographic measurement of EAT is preferable due to low costs, high availability and reproducibility, noninvasiveness, and no exposure to radiation. ${ }^{73}$

\section{STUDY LIMITATIONS}

Although initially we sought to conduct a systematic review of studies that assessed EAT using echocardiography in comparison with cardiac CT, in the course of our search we found that there were few studies that used CT in emergency clinical settings for diagnosing and managing acute coronary syndromes.

Secondly, cut-off values for epicardial fat have not been reproduced, due mainly to the fact that there are assorted descriptions of EF aggregation reported in the literature.

The power of this systematic review, in common with similar studies, is limited by the quality of the incorporated manuscripts, the study designs, and the statistical methods that had been used.

Regardless of these limitations, we are of the opinion that the study provides insights into the role of EAT in diagnosing and managing patients with acute coronary syndromes.

\section{CONCLUSIONS}

Epicardial adipose tissue, evaluated either by thickness using echocardiography, or by volume using cardiac CT, is associated with the severity of coronary stenosis, with the clinical and angiographic risk scores for acute coronary syndromes, and also with indicators of coronary reperfusion. Information provided by epicardial fat tissue can be used as predictors of major cardiovascular events in patients with acute coronary syndromes, over both short and long term.

\section{CONFLICT OF INTEREST}

Nothing to declare. 


\section{ACKNOWLEDGEMENT}

This research was supported via the research grant no. 103545/2016, contract number 43/05.09.2016, entitled "High performance multimodal MRI/CT imaging platform, for applications in computational medicine, nanoparticles and hybrid imaging for the research of atherothrombotic disorders - CARDIO IMAGE" financed by the Romanian Ministry of European Funds, the Romanian Government and the European Union.

\section{REFERENCES}

1. World Health Organization, Cardiovascular disease (CVDs), 2016. Available from: http://www.who.int/mediacentre/ factsheets/fs317/en/\#

2. Nakanishi K, Fukuda S, Tanaka A, et al. Epicardial Adipose Tissue Accumulation Is Associated with Renal Dysfunction and Coronary Plaque Morphology on Multidetector Computed Tomography. Circ J. 2015;80:196-201. doi: 10.1253/circj.CJ-150477.

3. Sacks H, Fain J. Human epicardial fat: what is new and what is missing? Clin Exp Pharmacol Physiol. 2011;38:879-887. doi: 10.1111/j.1440-1681.2011.05601.x.

4. Antonopoulus A, Antoniades C. The role of epicardial adipose tissue in cardiac biology: classic concepts and emerging roles. 2017. doi:10.1113/JP273049. [Epub ahead of print]

5. Alexopoulus N, Raggi P. Epicardial Adipose Tissue: Another Tassel in the Complex Fabric of Atherosclerosis. Cardiovasc Hematol Disord Drug Targets. 2017. PMID: 28124603. [Epub ahead of print]

6. Cheng $\mathrm{KH}, \mathrm{Chu} \mathrm{CS}$, Lee $\mathrm{KT}$, et al. Adipocytokines and proinflammatory mediators from abdominal and epicardial adipose tissue in patients with coronary artery disease. Int J Obes. 2008;32:268-274. doi: 10.1038/sj.ijo.0803726.

7. Talman A, Psaltis P, Cameron D, et al. Epicardial adipose tissue: far more than a fat depot. Cardiovasc Diagn Ther. 2014;4(6):416-429. doi: 10.3978/j.issn.2223-3652.2014.11.05.

8. MazurekT, Zhang L, Zalewski A, et al. Human epicardial adipose tissue is a source of inflammatory mediators. Circulation. 2003;108: 2460-2466. doi: 10.1161/01.CIR.0000099542.57313. C5.

9. Iacobellis G, Pistilli D, Gucciardo M, et al. Adiponectin expression in human epicardial adipose tissue in vivo is lower in patients with coronary artery disease. Cytokine. 2005;29:251-255. doi: 10.1016/j.cyto.2004.11.002.

10. Hodas R, Pop S, Opincariu D, et al. Correlations Between Severity of Coronary Lesions and Epicardial Fat Volume in Patients with Coronary Artery Disease - a Multislice CTbased Study. Journal of Interdisciplinary Medicine. 2016;1:7178. doi: 10.1515/jim-2016-0014.

11. Iacobellis G, Corradi D, Sharma AM. Epicardial adipose tissue: anatomic, biomolecular and clinical relationship with the heart. Nat Clin Pract Cardiovasc Med. 2005;2:536-543. doi: 10.1038/ncpcardio0319.

12. Gitsioudis G, Schmahl C, Missiou A, et al. Epicardial adipose tissue is associated with plaque burden and composition and provides incremental value for the prediction of cardiac outcome. A clinical cardiac computed tomography angiography study. PLoS One. 2016;11:e0155120. doi: 10.1371/ journal.pone.0155120.

13. Nakanishi R, Rajani R, Cheng VY, et al. Increase in epicardial fat volume is associated with greater coronary artery calcification progression in subjects at intermediate risk by coronary calcium score: a serial study using non-contrast cardiac CT. Atherosclerosis. 2011;218:363-368. doi: 10.1016/j. atherosclerosis.2011.07.093.

14. Bettencourt N, Toschke A, Leite D, et al. Epicardial adipose tissue is an independent predictor of coronary atherosclerotic burden. International Journal of Cardiology. 2012;158:26-32. doi: 10.1016/j.ijcard.2010.12.085.

15. Mahabadi A, Berg M, Lehmann N, et al. Association of Epicardial Fat With Cardiovascular Risk Factors and Incident Myocardial Infarction in the General Population: The Heinz Nixdorf Recall Study. Journal of the American College of Cardiology. 2013;61:1388-1395. doi: 10.1016/j.jacc.2012.11.062.

16. Nakanishi K, Fukuda S, Tanaka A, et al. Persistent epicardial adipose tissue accumulation is associated with coronary plaque vulnerability and future acute coronary syndrome in nonobese subjects with coronary artery disease. Atherosclerosis. 2014;237:353-60. doi: 10.1016/j.atherosclerosis.2014.09.015.

17. Subbotin V. Neovascularization of coronary tunica intima (DIT) is the cause of coronary atherosclerosis. Lipoproteins invade coronary intima via neovascularization from adventitial vasa vasorum, but not from the arterial lumen: a hypothesis. Theor Biol Med Model. 2012;9:11. doi: 10.1186/1742-4682-9-11.

18. Arad Y, Goodman K, Roth M, Newstein D, Guerci A. Coronary calcification, coronary disease risk factors, C-reactive protein, and atherosclerotic cardiovascular disease events: the St. Francis Heart Study. JACC. 2005;46:158-65. doi: 10.1016/j. jacc.2005.02.088.

19. Tamarappoo B, Dey D, Shmilovich $H$, et al. Increased pericardial fat volume measured from non-contrast CT predicts myocardial ischemia by SPECT. JACC Cardiovasc Imaging. 2010;3:1104-e1112. doi: 10.1016/j.jcmg.2010.07.014.

20. Doesch C, Süselbeck T, Haghi D, et al. The relationship between the severity of coronary artery disease and epicardial adipose tissue depends on the left ventricular function. PLoS One. 2012;7:e48330. doi: 10.1371/journal.pone.0048330.

21. Nakanishi K, Fukuda S, Tanaka A, et al. Persistent epicardial adipose tissue accumulation is associated with coronary plaque vulnerability and future acute coronary syndrome in nonobese subjects with coronary artery disease. Atherosclerosis. 2013;237:353-360. doi: 10.1016/j.atherosclerosis.2014.09.015.

22. Fukamachi D, Higuchi Y, Hiro T, et al. Association between the epicardial adipose tissue thickness and the presence of multivessel disease in patients with acute myocardial infarction. Journal of Atherosclerosis and Atherothrombosis. 2014;2:144-151. doi: 10.5551/jat.26120.

23. Bertaso A, Bertol D, Duncan B, Foppa M. Epicardial Fat: Definition, Measurements, and Systematic Review of Main Outcomes. Arq Bras Cardiol. 2013;101:18-28. doi: 10.5935/ abc. 20130138 .

24. Machann J, Thamer C, Schnoedt B, et al. Standardized assessment of whole body adipose tissue topography by MRI. J Magn Reson Imaging. 2005;21:455-62. doi: 10.1002/ jmri.20292.

25. Iacobellis G, Assael F, Ribaudo $M$, et al. Epicardial fat from echocardiography: a new method for visceral adipose 
tissue prediction. Obes Res. 2003;11:304-310. doi: 10.1038/ oby.2003.45.

26. Iacobellis G, Willens H. Echocardiographic Epicardial Fat: A Review of Research and Clinical Applications. J Am Soc Echocardiogr. 2009;22:1311-1319. doi: 10.1016/j. echo.2009.10.013.

27. Iacobellis G, Willens H, Barbaro G, Sharma AM. Threshold values of high risk echocardiographic epicardial fat thickness. Obesity (Silver Spring). 2008;16:887-892. doi: 10.1038/ oby.2008.6.

28. Iacobellis G, Singh N, Wharton S, Sharma A. Substantial changes in epicardial fat thickness after weight loss in severely obese subjects. Obesity (Silver Spring). 2008;16:1693-1697. doi: 10.1038/oby.2008.251.

29. Jeong J, Jeong M, Yun K, et al. Echocardiographic epicardial fat thickness and coronary artery disease. Circ J. 2007;71:536539. PMID: 17384455.

30. Saura D, Oliva MJ, Rodrı'guez D, Pascual-Figal DA, Hurtado JA, Pinar E, et al. Reproducibility of echocardiographic measurements of epicardial fat thickness. Int J Cardiol. 2010;141:311-313. doi: 10.1016/j.ijcard.2008.11.127.

31. Sarin S, Wenger C, Marwaha A, et al. Clinical significance of epicardial fat measured using cardiac multislice computed tomography. Am J Cardiol. 2008;102:767-771. doi: 10.1016/j. amjcard.2008.04.058.

32. Rosito GA, Massaro J, Hoffmann U, et al. Pericardial fat, visceral abdominal fat, cardiovascular disease risk factors, and vascular calcification in a community-based sample: the Framingham Heart Study. Circulation. 2008;117:605-613. doi: 10.1161/CIRCULATIONAHA.107.743062.

33. Shmilovich H, Dey D, Cheng V, et al. Threshold for the upper normal limit of indexed epicardial fat volume: derivation in a healthy population and validation in an outcomebased study. Am J Cardiol. 2011;108:1680-5. doi: 10.1016/j. amjcard.2011.07.031.

34. Nelson M, Mookadam F, Thota V, et al. Epicardial fat: an additional measurement for subclinical atherosclerosis and cardiovascular risk stratification? J Am Soc Echocardiogr. 2011;24:339-345. doi: 10.1016/j.echo.2010.11.008.

35. Abbara S, Desai J, Cury R, Butler J, Nieman K, Reddy V. Mapping epicardial fat with multi-detector computed tomography to facilitate percutaneous trans-epicardial arrhythmia ablation. Eur J Radiol. 2006;57:417-22. doi: 10.1016/j.ejrad.2005.12.030.

36. Moher D, Liberati A, Tetzlaff J, Altman DG, PRISMA Group. Preferred reporting items for systematic reviews and metaanalyses: the PRISMA statement. BMJ. 2009;339:b2535. doi: 10.1136/bmj.b2535.

37. Harada K, Amano T, Uetani T, et al. Cardiac 64-Multislice Tomography reveals Increased Epicardial Fat Volume in Patients with Acute Coronary Syndrome. Am J Cardiol. 2011;108:1119-1123. doi: 10.1016/j.atherosclerosis.2014.07.007.

38. Altun B, Colkesent Y, Gazi E, et al. Could Epicardial Adipose Tissue Thickness by Echocardiography be Correlated with Acute Coronary Syndrome Risk Scores. Echocardiography. 2013;30:1130-1134. doi: 10.1111/echo.12276.

39. Tanindi A, Kocaman S, Erkan A, et al. Epicardial adipose tissue thickness is associated with myocardial infarction and impaired coronary perfusion. Anatol J cardiol. 2015;15:224231. doi: 10.5152/akd.2014.5277.

40. Wang T, Liu Q Liu C, et al. Correlation of Echocardiographic Epicardial Fat Thickness with Severity of Coronary Artery
Disease in Patients with Acute myocardial infarction. Echocardiography. 2014;31:1177-1181. doi: 10.1111/echo.1254.

41. Sen F, Yilmaz S, Balci K, et al. The Relationship Between Epicardial Adipose Tissue Thickness and Infarct-Related Artery Patency in Patients with ST-segment Elevation Myocardial Infarction. Angiology. 2016;67:281-286. doi: 10.1177/0003319715591330.

42. Tscharre M, Hauser C, Rohla M, et al. Epicardial adipose tissue and cardiovascular outcome in patients with acute coronary syndrome undergoing percutaneous coronary intervention. Eur Heart J: Acute Cardiovascular Care. 2016. pii: 2048872616680609. [Epub ahead of print]

43. Gul I, Zungur M, Aykan A, et al. The relationship between GRACE score and Epicardial Fat thickness in non-STEMI Patients. Arq Bras cardiol. 2016;106:194-200. doi: 10.5935/ abc.20160024.

44. Ozcan F, Turak O, Canpolat U, et al. Association of epicardial fat thickness with TIMI risk score in NSTEMI/USAP patients. Herz. 2013;39:755-760. doi: 10.1007/s00059-013-3914-z.

45. Zencirci E, Zencirci A, Degirmencioglu A, et al. The relationship between epicardial adipose tissue and ST-segment resolution in patients with acute ST-segment elevation myocardial infarction undergoing primary percutaneous coronary intervention. Heart Vessels. 2014;2:147-153. doi: 10.1007/ s00380-013-0459-2.

46. De Larochelliere E, Cote J, Gilbert G, et al. Visceral/epicardial adiposity in non-obese and apparently healthy young adults: association with the cardiometabolic profile. Atherosclerosis. 2014;234:23-29. doi: 10.1016/j.atherosclerosis.2014.01.053.

47. Pierdomenico SD1, Pierdomenico AM, Neri M, Cuccurullo F. Epicardial adipose tissue and metabolic syndrome in hypertensive patients with normal body weight and waist circumference. Am J Hypertens. 2014;24:1245-1249. doi: 10.1038/ajh.2011.134.

48. Rabkin SW. The relationship between epicardial fat and indices of obesity and the metabolic syndrome: a systematic review and meta-analysis. Metab Syndr Relat Disord. 2014;12:31-42. doi: 10.1089/met.2013.0107.

49. Opincariu D, Mester A, Dobra M, et al. Prognostic Value of Epicardial Fat Thickness as a Biomarker of Increased Inflammatory Status in Patients with Type 2 Diabetes Mellitus and Acute Myocardial Infarction. Journal of Cardiovascular Emergencies. 2016;2:11-18. doi: 10.1515/jce-2016-0003.

50. Takase H, Dohi Y, Okado T, Hashimoto T, Goto Y, Kimura G. Effects of ezetimibe on visceral fat in the metabolic syndrome: a randomized controlled study. Euro J Clin Invest. 2012;42:1287-1294. doi: 10.1111/eci.12000.

51. Kim M, Tanaka K, Kim M, et al. Epicardial fat tissue: relationship with cardiorespiratory fitness in men. Med Sci Sports Exerc. 2010;42:463-469. doi: 10.1249/MSS.ob013e3181b8b1fo.

52. Park J, Park Y, Kim Y, et al. Effects of statins on the epicardial fat thickness in patients with coronary artery stenosis underwent percutaneous coronary intervention: comparison of atorvastatin with simvastatin/ezetimibe. J Cardiovasc Ultrasound. 2010;18:121-126. doi: 10.4250/jcu.2010.18.4.121.

53. Bo X, Ma L, Fan J, et al. Epicardial fat volume is correlated with coronary lesion and its severity. Int J Clin Exp Med. 2015;8:4328-4334. PMID: 26064349.

54. Park J, Choi S, Zheng $M$, et al. Epicardial adipose tissue thickness is a predictor for plaque vulnerability in patients with significant coronary artery disease. Atherosclerosis. 2013;226:134-139. doi: 10.1016/j.atherosclerosis.2012.11.001. 
55. Ahn S, Lim H, Joe D, et al. Relationship of epicardial adipose tissue by echocardiography to coronary artery disease. Heart. 2008;94:e7. doi:10.1136/hrt.2007.118471.

56. Alexopoulus N, McLean D, Janik M, Arepalli C, Stillman A, Raggi p. Epicardial adipose tissue and coronary artery plaque characteristics. Atherosclerosis. 2010;210:150-154. doi: 10.1016/j.atherosclerosis.2009.11.020.

57. Benedek T, Gyöngyösi M, Benedek I. Multislice Computed Tomographic Coronary Angiography for Quantitative Assessment of Culprit Lesions in Acute Coronary Syndromes. Can J Cardiol. 2013;29:364-371. doi: 10.1016/j.cjca.2012.11.004.

58. Maurovich-Horvat P, Schlett CL, Alkadhi H, et al. The napkin-ring sign indicates advanced atherosclerotic lesions in coronary CT angiography. JACC Cardiovasc Imaging. 2012;5:1243-1252. doi: 10.1016/j.jcmg.2012.03.019.

59. Benedek T, Mester A, Benedek A, Rat N, Opincariu D, Chițu M. Assessment of Coronary Plaque Vulnerability in Acute Coronary Syndromes using Optical Coherence Tomography or Intravascular Ultrasound. A systematic Review. Journal of Cardiovascular Emergencies. 2016;2:173-184. doi: 10.1515/ jce2016-0028.

60. Jang IK. Optical Coherence Tomography or Intravascular Ultrasound? JACC: Cardiovascular Interventions. 2011;4:492494. doi: 10.1016/j.jcin.2011.02.004.

61. Tian J, Ren X, Vergallo R, et al. Distinct morphological features of ruptured culprit plaque for acute coronary events compared to those with silent rupture and thin-cap fibroatheroma: a combined optical coherence tomography and intravascular ultrasound study. J Am Coll Cardiol. 2014;63:2209-2216. doi: 10.1016/j.jacc.2014.01.061.

62. Ding J, Hsu F, Harris T, et al. The association of pericardial fat with incident coronary heart disease: the Multi-Ethnic Study of Atherosclerosis (MESA). Am J Clin Nutr. 2009;90:499-504. doi: 10.3945/ajcn.2008.27358.

63. Granger C, Goldberg R, Dabbous O, et al. Predictors of hospital mortality in the Global Registry of Acute Coronary Events. Arch Intern Med. 2003;163:2345-2353. doi: 10.1001/ archinte.163.19.234.

64. Palmerini T, Genereux P, Caixeta A, et al. Prognostic value of the SYNTAX score in patients with acute coronary syndromes undergoing percutaneous coronary intervention: Analysis from the ACUITY (Acute Catheterization and Urgent Intervention Triage StrategY) trial. J Am Coll Cardiol. 2011;57:2389-2397. doi: 10.1016/j.jacc.2011.02.032.

65. Antman E, Cohen M, Bernink P, et al. The TIMI risk score for unstable angina/non-ST elevation MI: a method for prognostication and therapeutic decision making. JAMA. 2000;284:835-842. doi: 10.1001/jama.284.7.835.

66. de Lemos JA, Braunwald E. ST segment Resolution as a Tool for Assessing the Efficacy of Reperfusion Therapy. J Am Coll Cardiol. 2001;38:1283-1294. doi: 10.1016/S07351097(01)01550-9.

67. Opincariu D, Chitu M, Rat N, Benedek I. Integrated ST Segment Elevation Scores and In-hospital Mortality in STEMI Patients Undergoing Primary PCI. Journal of Cardiovascular Emergencies. 2016;2:114-121. doi: 10.1515/jce-2016-0018.

68. Husser O, Bodi V, Sanchis J, et al. White blood cell subtypes after STEMI: temporal evolution, association with cardiovascular magnetic resonance-derived infarct size and impact on the outcome. Inflammation. 2011;34:73-84. doi: 10.1007/s10753010-9209-0.

69. Odeberg J, Freitag $M$, Forssell $\mathrm{H}$, et al. Influence of preexisting inflammation on the outcome of acute coronary syndrome: a cross-sectional study. 2016;5:e009968. doi: 10.1136/bmjopen-2015-009968.

70. Tanindi A, Erkan A, Ekici B. Epicardial adipose tissue thickness can be used to predict major adverse cardiac events. Coronary Artery Disease. 2015;26:686-691. doi: 10.1097/ MCA.0000000000000296.

71. Hajsadeghi F, Nabavi V, Bhandari A, et al. Increased epicardial adipose tissue is associated with coronary artery disease and major adverse cardiovascular events. Atherosclerosis. 2014;237:486-489. doi: 10.1016/j.atherosclerosis.2014.09.037.

72. Cheng V, Dey D, Tamarappoo B, et al. Pericardial fat burden on ECG-gated non-contrast CT in asymptomatic patients who subsequently experience adverse cardiovascular events. JACC Cardiovasc Imaging. 2010;3:352-360. doi: 10.1016/j. jcmg.2009.12.013.

73. Yamada H, Sata M. Does Echocardiographic Epicardial Adipose Tissue Thickness become a Usefull Biomarker? Journal of Atheroscler and Thromb. 2015;22:555-556. doi: 10.5551/jat. ED01. 